\title{
HUBUNGAN MANAJEMEN AKTIF KALA III DENGAN PERDARAHAN PADA SAAT PERSALINAN DI RUANG BERSALIN RSUD DR. SOEKARDJO KOTA TASIKMALAYA OKTOBER 2014 - APRIL TAHUN 2015
}

Oleh:

Widya Maya Ningrum S.ST., M.Kes

\section{A. Abstrak}

Penyebab kematian ibu secara langsung adalah perdarahan (39\%), eklampsia (24\%), infeksi $(11 \%)$ dan lain-lain (26\%) dan penyebab tidak langsung Kurang Energi Kronis (37\%), Anemia pada kehamilan (40\%). Perdarahan pada saat persalinan merupakan penyebab kematian ibu yang paling sering terjadi, dengan tanda-tanda nya adalah keluar darah dari jalan lahir dalam jumlah banyak>500 cc terjadi dalam waktu 24 jam setelah persalinan berlangsung (Manuaba, 2004:296). Mencegah perdarahan pada saat persalinan dimulai dari tahap yang paling dini. Setiap pertolongan persalinan harus menerapkan upaya pencegahan perdarahaan dengan melakukan Manajemen Aktif Kala (MAK) III. Berdasarkan data yang diperoleh dari profil RSUD dr Soekardjo Kota Tasikmalaya tahun 2013, bahwa terdapat kasus perdarahan pada saat persalinan sebanyak 87 kasus, dengan penyebab atonia uteri 79 kasus (90\%), retensio plasenta 8 kasus (10\%). Hal ini menunjukan bahwa kasus tersebut sangat tinggi dan berkontribusi terhadap kesakitan dan kematian ibu. Dari 87 kasus ibu yang mengalami perdarahan pada saat persalinan 10 kasus tidak tertolong. Tujuan penelitian ini mengetahui Hubungan Manajemen Aktif Kala III dengan Perdarahan pada saat persalinan Di Ruang Bersalin RSUD dr. Soekardjo Kota Tasikmalaya Oktober 2014 - April Tahun 2015.

Penelitian ini merupakan penelitian survey dengan tekhnik potong silang (cross sectional). Dengan rancangan ini informasi mengenai manajemen aktif kala III diperoleh secara bersamaan dengan perdarahan pada saat persalinan. Populasi dalam penelitian ini adalah seluruh ibu bersalin dengan proses persalinan pervaginam di RSUD dr. Soekardjo Tasikmalaya, dengan sample penelitian ini menggunakan accidental sampling, yaitu ibu bersalin periode Juli-Desember 2015.

Hasil penelitian menyatakan bahwa sebagaian besar ibu bersalin di RSUD dr Soekardjo dilakukan manajeman Aktif Kala III (67,91\%). Dari 268 ibu bersalin38 orang ( $14,18 \%)$ mengalami perdarahan. Serta ada hubungan antara manajeman aktif kala III dengan ibu yang mengalami perdarahan di RSUD dr Soekardjo hal ini sesua dengan hasil uji statistik Chi-Square dengan tingkat kepercayaan $95 \%(\alpha=0,05)$ dengan menunjukan nilai $P=0,027(p \leq 0,05)$.

Berdasarkan bukti - bukti pengelolaan aktif kala III telah memberikan hasil terhadap penurunan resiko kasus perdarahan post partum. Mengingat indonesia merupakan negara dengan geografis yang sulit dimana kematian ibu karena 3 terlambat masih banyak maka pemerintah perlu mengadakan kebijakan tegas penerapan manajemen aktif kala III pada ibu bersalin.

\section{Kata Kunci: Manajemen aktif Kala III, Perdarahan}




\section{B. Latar Belakang}

Berdasarkan Survey Demografi dan Kesehatan Indonesia (SDKI) Angka Kematian Ibu (AKI) per 100.000 kelahiran hidup menurun secara bertahap, dari 390/100.000 (tahun 1991), menjadi 334/100.000 (tahun 1997), dan 228/100.000 (tahun 2007). Tahun 2012 untuk pertama kalinya AKI melonjak menjadi359/100.000 kelahiran, hal ini menunjukan masih jauhnya pencapaian MDGs pada tahun 2015 yaitu $102 / 100.000$ kelahiran hidup untuk AKI. (SDKI, 2012).

Penyebab kematian ibu secara langsung adalah perdarahan (39\%), eklampsia (24\%), infeksi (11\%) dan lainlain $(26 \%)$ dan penyebab tidak langsung Kurang Energi Kronis (37\%), Anemia pada kehamilan $(40 \%)$. Perdarahan pada saat persalinan merupakan penyebab kematian ibu yang paling sering terjadi, dengan tanda-tanda nya adalah keluar darah dari jalan lahir dalam jumlah banyak $>500 \mathrm{cc}$ terjadi dalam waktu 24 jam setelah persalinan berlangsung (Manuaba, 2004:296).

Mencegah perdarahan pada saat persalinan dimulai dari tahap yang paling dini. Setiap pertolongan persalinan harus menerapkan upaya pencegahan perdarahaan dengan melakukan Manajemen Aktif Kala (MAK) III. Tujuan MAK III adalah untuk menghasilkan kontraksi uterus yang lebih efektif sehingga dapat mempersingkat waktu, mencegah perdarahan, dan mengurangi kehilangan darah kala tiga persalinan. Sebagian besar kasus kesakitan dan kematian ibu di Indonesia disebabkan oleh perdarahan pada saat persalinan dimana sebagian besar disebabkan oleh atonia uteri dan retensio plasenta yang sebenarnya dapat dicegah

\section{Metode}

Penelitian ini merupakan penelitian survey dengan tekhnik potong silang (cross sectional). Dengan rancangan ini informasi mengenai manajemen aktif kala III diperoleh secara bersamaan dengan perdarahan pada saat persalinan dengan melakukan manajemen aktif kala III.

Penelitian Prevention of Postpartum Hemorrhage Intervention tahun 2006 tentang praktik manajemen aktif kala III di 20 Rumah sakit di Indonesia, menunjukan bahwa hanya $30 \%$ rumah sakit melaksanakan hal tersebut. Hal ini sangat berbeda jika dibandingkan dengan praktik manajemen aktif di tingkat pelaynan kesehatan primer ( Bidan Praktik Mandiri), sekitar $70 \%$ melaksanakan menejemen aktif kala III terhadap ibu - ibu yang ditangani. Jika ingin menyelamatkan banyak ibu bersalin maka sudah sewajarnya jika manajemen aktif kala III ini tidak hanya dilatihkan tetapi juga dipraktikan dan menjadi standar asuhan persalinan.

Berdasarkan data yang diperoleh dari profil RSUD dr Soekardjo Kota Tasikmalaya tahun 2013, bahwa terdapat kasus perdarahan pada saat persalinan sebanyak 87 kasus, dengan penyebab atonia uteri 79 kasus $(90 \%)$, retensio plasenta 8 kasus (10\%). Hal ini menunjukan bahwa kasus tersebut sangat tinggi dan berkontribusi terhadap kesakitan dan kematian ibu. Dari 87 kasus ibu yang mengalami perdarahan pada saat persalinan 10 kasus tidak tertolong. Meskipun angkanya sedikit namum hal ini seharusnya tidak terjadi apabila penolong persalinan menerapkan manajemen aktif kala III dalam standar asuhan persalinan.

Tujuan dari penelitian ini adalah mengetahui Hubungan Manajemen Aktif Kala III dengan Perdarahan pada saat persalinan Di Ruang Bersalin RSUD dr. Soekardjo Kota Tasikmalaya Oktober 2014 - April Tahun 2015.

Populasi dalam penelitian ini adalah seluruh ibu bersalin dengan proses persalinan pervaginam di RSUD $\mathrm{dr}$. Soekardjo Tasikmalaya, dengan sample penelitian ini menggunakan accidental sampling, yaitu ibu bersalin periode Jul $i-$ Desember 2015. 
Variabel dalam penelitian ini diantaranya variable independent yaitu manajemen aktif kala III dan variabel dependent yaitu perdarahan pada saat persalinan

\section{Hasil Penelitian}

1. Deskripsi Subjek Penelitian Penelitian dilakukan di Ruang Bersalin RSU dr. Soekardjo Kota
Instrumen dalam penelitian ini menggunakan format checlist untuk mendapatkan data tentang manajemen aktif kala III dan spignomanometer untuk mengukur perkiraan jumlah kehilangan darah pada ibu bersalin.

Tasikmalaya. Adapun subjek yang diteliti terdiri dari 268 orang subjek dengan karakteristik yang berbeda yang diantaranya adalah sebagai berikut :

Tabel. 5.1 Karakteristik responden

\begin{tabular}{|c|c|c|}
\hline Karakteristik & Kategori & Jumlah \\
\hline & 1. Primipara & 102 \\
\hline Paritas & 2. Multipara & 130 \\
\hline & 3. Grandemultipara & 36 \\
\hline Umur & $\begin{array}{l}\text { 1. Tidak berisiko } \\
\text { 2. Risiko }\end{array}$ & $\begin{array}{l}157 \\
111\end{array}$ \\
\hline
\end{tabular}

2. Manajemen aktif kala III

Hasil penelitian mengenai Gambaran manajemen Aktif Kala III di Ruang bersalin dr. Soekardjo Kota Tasikmalaya periode Oktober 2014 - April Tahun 2015, sebagai berikut:
Tabel 5.2 Distribusi frekuensi manajemen Aktif Kala III di Ruang bersalin rumah sakit umum dr. Soekardjo Kota Tasikmalaya periode Oktober 2014 - April Tahun 2015

\begin{tabular}{cccc}
\hline Kategori & Jumlah & \% \\
\hline 1. & Sesuai standar & 182 & 67,91 \\
2. & Tidak sesuai standar & 86 & 32,09 \\
\hline \multirow{2}{*}{ Jumlah } & 268 & 100 \\
\hline
\end{tabular}

Sebagaian besar ibu bersalin di RSUD dr Soekardjo dilakukan manajeman Aktif Kala III 67,91

3. Perdarahan pada saat persalinan Hasil penelitian mengenai perdarahan pada saat persalinan di Ruang bersalin dr. Soekardjo Kota Tasikmalaya periode Oktober 2014 - April Tahun 2015, sebagai berikut:
Tabel $5.3 \quad$ Distribusi frekuensi perdarahan pada saat persalinan di Ruang bersalin rumah sakit umum dr. Soekardjo Kota Tasikmalaya periode Oktober 2014 - April Tahun 2015 


\begin{tabular}{|c|c|c|}
\hline Kategori & Jumlah & $\%$ \\
\hline 1. Tidak & 230 & 85,82 \\
\hline 2. $\mathrm{Ya}$ & 38 & 14,18 \\
\hline Jumlah & 268 & 100 \\
\hline
\end{tabular}

Dari 268 ibu bersalin38 orang ( 14,18

$\%)$ mengalami perdarahan

4. Hubungan Manajeman Aktif Kala III dengan Perdarahan Pasca Persalinan

Hasil penelitian mengenai Hubungan Manajeman Aktif Kala III dengan Perdarahan Pasca Persalinandi Ruang bersalin dr. Soekardjo Kota Tasikmalaya periode Oktober 2014 - April Tahun 2015, sebagai berikut:

Tabel 5.3 Distribusi frekuensi Hubungan Manajeman Aktif Kala III dengan Perdarahan Pasca Persalinan di Ruang bersalin rumah sakit umum dr. Soekardjo Kota Tasikmalaya periode Oktober 2014 - April Tahun 2015

\begin{tabular}{|c|c|c|c|c|c|c|}
\hline No & kategori & $\begin{array}{c}\text { Tidak } \\
\text { perdarahan }\end{array}$ & $\%$ & $\begin{array}{c}\text { Ya } \\
\text { perdarahan }\end{array}$ & $\%$ & $\begin{array}{c}\mathbf{P} \\
\text { value }\end{array}$ \\
\hline 1. & $\begin{array}{l}\text { Sesuai } \\
\text { standar }\end{array}$ & 102 & 44,3 & 9 & 23,7 & \multirow[t]{3}{*}{0,027} \\
\hline 2. & $\begin{array}{l}\text { Tidak sesua } \\
\text { standar }\end{array}$ & 128 & 55,7 & 29 & 76,3 & \\
\hline & Jumlah & 230 & 100 & 38 & 100 & \\
\hline
\end{tabular}

Ada hubungan antara manajeman aktif kala III dengan ibu yang mengalami perdarahan di RSUD dr Soekardjo hal ini sesua dengan hasil uji statistik Chi-

\section{E. Pembahasan}

Hasil penelitian yang dilakukan di RSUD dr Soekardjo Kota Tasikmalaya periode Oktober 2014 - April Tahun 2015 menunjukkan bahwa sebagian besar responden $(58,6 \%)$ termasuk dalam kategori umur berisiko. Wanita yang berumur kurang dari 20 tahun dan lebih dari 35 tahun, mempunyai risiko yang tinggi untuk hamil dan melahirkan, karena akan membahayakan kesehatan dan keselamatan ibu hamil maupun janinnya, berisiko mengalami retensio plasenta. Hal ini disebabkan pada umur 35 tahun sering mengalami kekakuan jaringan sehingga miometrium juga tidak dapat bekerja dengan maksimal. Paritas. Hasil penelitian yang dilakukan di Dr Soekardjo Kota Tasikmalaya periode
Square dengan tingkat kepercayaan $95 \%$ $(\alpha=0,05)$ dengan menunjukan nilai $\mathrm{P}=$ $0,027(\mathrm{p} \leq 0,05)$

Oktober 2014 - April Tahun 2015 menunjukkan bahwa sebagian besar responden $(48,5 \%)$ termasuk kategori multipara. Wanita dengan jumlah paritas lebih dari 3 berisiko dengan kehamilan dan persalinan tinggi. Hal ini sesuai dengan teori Nugroho (2011) yang menyatakan bahwa paritas (multi/grande multipara) merupakan faktor penyebab umum terjadinya perdarahan pasca salin . Menurut Saifudin (2009) paritas yang berpotensi mengalami perdarahan pasca salin adalah pada multipara dan grandemultipara. Pada multipara terjadi kemunduran dan cacat pada endometrium yang mengakibatkan terjadinya fibrosis pada bekas implantasi plasenta pada persalinan persalinan sebelumnya, sehingga vaskularisasi menjadi 
berkurang.Untuk memenuhi kebutuhan nutrisi janin, plasenta adhesive sampai parkreta. Selain itu juga, pada multipara dan grandemultipara terjadi penurunan elastisitas uterus sehingga myometrium tidak dapat berkontraksi dan beretraksi dengan maksimal yang mengakibatkan terjadinya perdarahan pasca salin. Manajemen aktif kala III Hasil penelitian yang dilakukan di Dr Soekardjo Kota Tasikmalaya periode Oktober 2014 April Tahun 2015 menunjukkan bahwa $2,1 \%$ responden tidak dilakukan Manajemen Aktif Kala III.Hal ini menunjukkan bahwa tidak dilakukan manajemen aktif kala III meningkatkan risiko perdarahan selama proses persalinan dan kesalahan manajemen kala tiga persalinan, seperti manipulasi dari uterus yang tidak perlu sebelum terjadinya pelepasan dari plasenta menyebabkan kontraksi yang tidak ritmik, pemberian uterotonik yang tidak tepat waktunya yang juga dapat menyebabkan serviks kontraksi dan menahan plasenta, serta pemberian anestesi yang melemahkan kontraksi uterus. WHO telah merekomendasikan agar dokter dan bidan melaksanakan Manajemen Aktif Kala III dalam Asuhan Persalinan Normal, karena dengan Manajemen Aktif Kala III banyaknya darah yang hilang dapat berkurang sehingga dapat mengurangi angka kematian dan angka kesakitan yang berhubungan dengan perdarahan. Kejadian perdarahan pasca salin Hasil penelitian yang dilakukan di Dr Soekardjo Kota Tasikmalaya periode Oktober 2014 - April Tahun 2015 menunjukkan bahwa responden $(14,2 \%)$ mengalami perdarahan pasca salin. Hal ini menunjukkan bahwa kejadian perdarahan pasca salin menurun namun persentase kejadian masih tinggi (diatas 10\%) dari keseluruhan persalinan. Pada tahun 2011 tercatat 99 persalinan, dengan kejadian perdarahan pasca salin sebanyak 15 kasus $(15,1 \%)$. Pada tahun 2012 terdapat 93 persalinan, dengan kejadian perdarahan pasca salin sebanyak 20 kasus (21,5\%), dan pada tahun 2013 tercatat 268 persalinan, dan 38 kasus(14,1\%) diantaranya mengalami perdarahan pasca salin. Kejadian perdarahan pasca salin merupakan komplikasi dalam persalinan yang menduduki pertama dalam kematian ibu di Indonesia oleh karena itu memerlukan perhatian khusus.

Hubungan manajemen aktif kala III dengan perdarahan pasca salin pada ibu bersalin. Hasil analisis statistik uji Chi• Square dengan tingkat kepercayaan 95\% $(\alpha=0,05)$ menunjukkan nilai $\mathrm{p}=0,027$ $(\mathrm{p}<0,05)$, maka secara simultan ada hubungan antara manajemen aktif kala III dengan kejadian perdarahan pasca salin di RSUD drt Soerkadjo. Hal ini menunjukkan bahwa dampak yang mungkin terjadi jika manajemen aktif tidak dilakukan adalah kala III persalinan lebih panjang, jumlah kehilangan darah lebih banyak, kejadian perdarahan pasca salin mungkin lebih cenderung terjadi. Manajemen aktif kala III persalinan mempercepat kelahiran plasenta dan dapat mencegah atau mengurangi perdarahan postpartum terutama retensio plasenta. Menurut Saifudin (2009) waktu yang paling kritis untuk mencegah perdarahan postpartum yang disebabkan oleh retensio plasenta adalah ketika plasenta lahir dan segera setelah itu. Ketika plasenta terlepas atau sepenuhnya terlepas tetapi tidak keluar, maka perdarahan terjadi di belakang plasenta sehingga uterus tidak dapat sepenuhnya berkontraksi karena plasenta masih di dalam. 


\section{F. Simpulan dan Saran}

1. SIMPULAN

a. Sebagaian besar ibu bersalin di RSUD dr Soekardjo dilakukan manajeman Aktif Kala III 67,91

b. Dari 268 ibu bersalin38 orang ( $14,18 \%$ mengalami perdarahan

c. Ada hubungan antara manajeman aktif kala III dengan ibu yang mengalami perdarahan di RSUD $\mathrm{dr}$ Soekardjo hal ini sesua dengan hasil uji statistik Chi- Square dengan tingkat kepercayaan 95

\section{G. Referensi}

Cunningham, F. G. 2006. Obstetri Williams. Jakarta: EGC.

Depkes RI.2010. Profil kesehatan Indonesia 2001 Menuju Indonesia sehat. 2010. Jakarta:Departemen Kesehatan Harmia, Elvira. 2010. Sikap dan Tindakan Bidan Terhadap Penanganan Retensio Plasenta di Desa Terjun Kecamatan Medan Marelan . Medan: Program D IV Bidan Pendidik Fakultas Keperawatan Universitas Sumat Hidayat, A.A.A. 2012. Metodelogi Penelitian Kebidanan Tehnik Analisis Data. Jakarta : Salemba Medika.

JNPK-KR 2012. Asuhan Persalinan Normal, Asuhan Esensial Bagi Dinamika Kesehatan, Vol.14 Desember 2014 Umur, Paritas dan Manajemen Aktif Kala III Ibu Bersalin dan Bayi Baru Lahir Serta Penatalaksanaan Komplikasi Segera Pasca Persalinan dan Nifas.

Manuaba, I.B.G, dkk. 2008. Gawat Darurat Obtetri Ginekologi dan Obstetri Ginekologi Sosial Untuk Profesi Bidan. Jakarta : EGC.

Manuaba. I.B.G, dkk. 2010. Ilmu Kebidanan, Penyakit Kandungan dan KB. Jakarta:EGC.
$\% \quad(\alpha=0,05)$ dengan menunjukan nilai $\mathrm{P}=0,027(\mathrm{p}$ $\leq 0,05)$

\section{SARAN}

Berdasarkan bukti - bukti pengelolaan aktif kala III telah memberikan hasil terhadap penurunan resiko kasus perdarahan post partum. Mengingat indonesia merupakan negara dengan geografis yang sulit dimana kematian ibu karena 3 terlambat masih banyak maka pemerintah perlu mengadakan kebijakan tegas penerapan manajemen aktif kala III pada ibu bersalin.

Notoatmodjo, Soekidjo. 2007. Promosi Kesehatan Teori dan Aplikasi. Jakarta :RinekaCipta.

Prawirohardjo, S. 2012. Ilmu Kebidanan. Jakarta: Yayasan Bina Pustaka. Profil Kesehatan

Rahmawati, EniNur. 2011. Ilmu Praktis Kebidanan. Jakarta : Victory IntiCipta.

Manuaba, I.B.G, dkk. 2008. Gawat Darurat Obtetri Ginekologi dan Obstetri Ginekologi Sosial Untuk Profesi Bidan. Jakarta : EGC.

Manuaba. I.B.G, dkk. 2010. Ilmu Kebidanan, Penyakit Kandungan dan KB. Jakarta:EGC.

Notoatmodjo, Soekidjo. 2007. Promosi Kesehatan Teori dan Aplikasi. Jakarta :RinekaCipta.

Prawirohardjo, S. 2012. Ilmu Kebidanan. Jakarta: Yayasan Bina Pustaka.

Profil Kesehatan RSUD dr Soekardjo tahun 2014

Prawirohardjo, Sarwono. 2007.

Varney, Hellen. 2010. Midwifery Ed.3. Jakarta : EGC.

Wawan A dan Dewi M. 2010. Pengetahuan, Sikap dan Perilaku Manusia. Yogyakarta: Nuha Medika. Winkjosastro. 2009.

Ilmu Kebidanan. Jakarta : Yayasan Bina Pustaka. 